\title{
A ReduÇão ho Gesto: Mira Schendel encontra Walter Benjamin
}

http://dx.doi.org/10.1590/1984-0292/1324

\author{
Ana Maria do Valle, Jô Gondar
}

Universidade Federal do Estado do Rio de Janeiro, Rio de Janeiro, RJ, Brasil

\section{Resumo}

O artigo analisa o trabalho da artista plástica suiço-brasileira Mira Schendel a partir de um conceito proposto por Walter Benjamin. Em Schendel, a busca por uma experiência primordial - um núcleo não representável que habita toda representação - se expressa pela redução a um gesto fundante, gesto este que costuma estar encoberto, nas artes em geral, por um excesso de adornos, metáforas e sentidos figurados. Este procedimento, descrito por Benjamin em seu ensaio sobre Kafka, foi por ele nomeado como redução ao gesto.O artigo procura explorar a potência deste conceito, trabalhando o modo como Schendel foi capaz de formalizá-lo plasticamente em sua obra.

Palavras-chave: gesto; representação; artes plásticas; Mira Schendel; Walter Benjamin.

\section{THE REDUCTION TO THE GESTURE: Mira Schendel meEts Walter Benjamin}

\begin{abstract}
The article uses a concept proposed by Walter Benjamin for understanding the artwork of Swiss-Brazilian painter Mira Schendel. In Schendel, the search for a primordial experience - a non representable core that inhabits each representation - is expressed by the reduction to a foundational gesture which is usually concealed by an excess of ornamentation, metaphors and figurative meanings. This procedure was described in Benjamin's essay on Kafka, where he calls it reduction to the gesture. The article tries to explore the power of this concept, working the way Schendel coul formalize it in her artwork.
\end{abstract}

Keywords: gesture; representation; fine arts; Mira Schendel; Walter Benjamin.

\footnotetext{
^Endereço para correspondência: Universidade Federal do Estado do Rio de Janeiro, Programa de Pós-Graduação em Memória Social. Av. Pasteur, 458 - térreo - sala T 05 - Urca. 22290024 - Rio de Janeiro, RJ - Brasil.E-mail: lirioanamariana@terra.com.br, jogondar@uol.com.br
} 
"Eu diria que a linha na maioria das vezes estimula o vazio. Não estou certa de que a palavra estimular esteja correta. Algo assim. De qualquer modo, o que importa na minha obra é o vazio, ativamente o vazio."

\section{Mira Schendel}

Toda narrativa é precária. É indiferente o material do qual é feita: seja literária ou pictórica, nenhuma narrativa consegue cernir a experiência real. Tentamos alcançá-la com palavras ou imagens, mas as próprias palavras e imagens impedem que a experiência possa ser atingida. Mais do que presentificar alguma coisa, uma narrativa torna presente a distância que dela nos separa. Ainda assim, existem os que se dispõem a enfrentar a impossibilidade, franqueando a distância que separa uma narrativa daquilo que ela narra. São autores que querem arrebentar a casca das palavras e das imagens para descobrir o segredo que elas escondem. São escritores, poetas ou pintores que pretendem conduzir o leitor ou o espectador a vislumbrar, por meio das palavras ou das imagens, algo que elas jamais poderiam dizer. Eles desejam transpor a separação entre a linguagem e as coisas, procurando atingir o fundamento rochoso da experiência.

$\mathrm{Na}$ literatura, autores como Clarice Lispector, Paul Celan e Franz Kafka fazem a narrativa buscar, sob formas diferentes, o osso da linguagem. $\mathrm{Na}$ pintura, Francis Bacon já havia dito que sua procura era pela brutalidade do fato (SYLVESTER, 1998). Neste artigo vamos abordar o trabalho de uma artista plástica, Mira Schendel, cuja busca por uma experiência primordial - um núcleo não representável que habita toda representação - se expressa pela redução a um gesto fundante, gesto que costuma, nas artes em geral, estar encoberto por um excesso de adornos, metáforas e sentidos figurados. Esse procedimento, já estudado por Walter Benjamin através da literatura de Kafka, foi nomeado pelo filósofo como "redução ao gesto". Ao trazer a noção para o campo da pintura, este artigo propõe o encontro entre o pensador alemão e a artista radicada no Brasil que, ao nosso ver, soube formalizar plasticamente o próprio gesto contido na noção benjaminiana. 


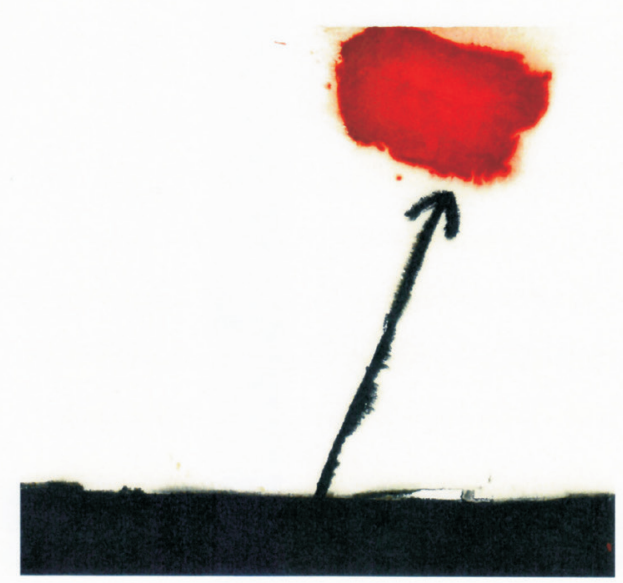

Fig. 1.

Sem Título, 1964

técnica mista sobre madeira

$92 \times 91 \mathrm{~cm}$

coleção particular

\section{Ativar o vazio}

Mira Schendel (1919-1988), artista plástica nascida na Suíça e radicada no Brasil, é considerada um dos maiores expoentes da arte contemporânea brasileira. Ao chegar em São Paulo na década de 50, Mira encontrou o campo das artes dominado pelo debate dos conceitos de arte moderna que deram início ao movimento Concreto. Porém o trabalho de Mira não se enquadrava em nenhuma das tendências em discussão. Caracterizava-se por uma economia que convocava a sensibilidade de maneira inusitada. Sobre isso escreve o crítico Guy Brett. (2001, p. 66):

Quando os desenhos de Mira Schendel foram expostos pela primeira vez em Londres, em meados da década de 1960, na Signals Gallery (inicialmente por recomendação de Sérgio Camargo), achei sua economia espantosa. O vazio radical da folha de papel era correspondido pela extrema delicadeza das marcas. Como objetos materiais, eles tinham uma qualidade única, que eu nunca vira nas artes gráficas, 
uma combinação de formato, quantidade, dimensão, papel utilizado e técnica de inscrição. Nesse período, Mira estava em pleno desenvolvimento de uma forma de produção que renovaria de modo especial a capacidade da arte como processo de sensibilização.

A obra de Mira Schendel quer alcançar algo fugaz, sutil. Combinando uma intensidade expressiva e uma economia de traços e cores, a artista quer apreender o inapreensível; seus trabalhos realizam esta renovada tentativa, estabelecendo assim um circuito sempre incompleto, inconcluso, inacabado. Ao lidar com algo de extrema delicadeza e ao realizar trabalhos que se materializam com acentuada intensidade, Mira estabelece um paradoxo. A intensidade aparece, entre outros aspectos, através de suas linhas, sempre muito atentas, reveladoras de uma presença impositiva; todavia, essas linhas muitas vezes se apresentam finas, quase fugidias. Esse paradoxo, intencional, aponta para a questão que define o trabalho da artista e os movimentos por ela realizados: "o que importa na minha obra é o vazio, ativamente o vazio" (BRETT, 2001, p. 174).

Ao ativar o vazio, Mira cria um universo próprio de ritmos e presença plástica. Evidenciar o vazio, ativá-lo, como nomeia a artista, faz com que ela organize e expresse plasticamente algo que nenhum traço ou linha pode representar - apenas estimular, como afirma Mira. É como se, na tentativa de transmitir e conter uma dimensão irrepresentável, um traço se dirigisse para a região do emudececimento. Há na estética de Mira Schendel um silêncio, um silêncio profundamente eloqüente por habitar o núcleo da palavra e da imagem. Esta forma única de expressão, esta forma de compor discrição e pregnância, economia e intensidade são traços característicos da obra de Schendel. Seus trabalhos ao longo do tempo possuem absoluta coerência compondo, assim, uma obra vivaz e silenciosa; firme, porém diáfana. Pensamos que esse universo schendiano pode ser lido de maneira rica através da noção de "redução ao gesto", conforme elaborada por Walter Benjamin. Mas para realizar esse encontro devemos, antes de qualquer outra coisa, apresentar a noção como Benjamin a pensou.

\section{A ReduÇão ho Gesto}

A noção de redução ao gesto não se encontra nitidamente explicitada na obra de Walter Benjamin. Encontramos em seu texto sobre Kafka algumas menções relevantes a respeito do que Benjamin entende como gesto. Eis a primeira:

O gesto é o elemento decisivo, o centro da ação [...] Kafka é sempre assim; ele priva os gestos humanos dos seus esteios tradicionais e os transforma em temas de reflexões intermináveis (BENJAMIN, 1996[1934], p. 147).

Nesta primeira citação, começamos a entrar em contato com a amplitude do tema. Benjamin nos indica que ao falar sobre o gesto trata de algo que escapa aos "esteios tradicionais" e atinge dimensões de "reflexões intermináveis", ou seja, dimensões que por serem de outra natureza ultrapassam o discurso trivial. 
A noção elaborada por Benjamin se refere a algo que não é possível ser dito de imediato, a uma esfera não passível de fácil ou rápida expressão; dela quase não se pode falar por não ser feita do material mais característico da linguagem, os significantes. Ainda assim é possível, através de aproximações sucessivas, rodear, circunscrever a noção. $O$ gesto expressa alguma coisa que não é narrável, mas que indica o próprio ato do narrar em seu sentido literal, naquilo que ele inaugura no real. Por este motivo, o gesto exige, para ser circunscrito, uma complexidade árdua de articulações apresentada por meio de imagens, sensações ou percepções imprecisas que não estejam comprometidas com a clareza ou com a justeza de uma racionalidade aplicada à utilidade ou à trivialidade das ações. O gesto em Benjamin quer tentar expressar em signos a natureza íntima das coisas, um ponto de origem sem definição. Para compor nossa reflexão e acompanhar o pensamento de Benjamin, encontramos no filósofo José Gil um trecho que se encaminha na mesma vertente. Em suas palavras:

A experiência primeira é a da imagem intensiva. Antes de a percepção se estabilizar, se fixar à distância e se impor, o mundo da primeira infância organiza-se em torno de vagas sensoriais num turbilhão, imprevisíveis. Antes da constância perceptiva, há as variações da imagem. Porque a sensação desabrocha em imagens, tal como a percepção: o bloco emotivo que as atravessa e as envolve mantém-nas ainda soldadas, indiferenciadas, sincronizadas (GIL, 2005, p. 23).

A artista plástica Mira Schendel descreve alguns de seus trabalhos nesta mesma clave de pensamento. O que será exposto a seguir é um fragmento de texto datilografado, não datado e não assinado, encontrado entre os papéis da artista. Este texto encontra-se reproduzido no livro No vazio do mundo: Mira Schendel, da crítica de arte Sonia Salzstein (SCHENDEL apud SALZTEIN, 1997, p. 256):

Os trabalhos ora apresentados são resultado de uma tentativa até agora frustrada de surpreender o discurso no momento da sua origem. O que me preocupa é captar a passagem da vivência imediata, com toda a sua força empírica, para o simbólico, com sua memorabilidade e relativa eternidade. Sei que se trata, no fundo, do seguinte problema: a vida imediata, aquela que sofro, e dentro da qual ajo, é minha, incomunicável, e, portanto sem sentido e sem finalidade. $\mathrm{O}$ reino dos símbolos que procuram captar essa vida (e que é o reino das linguagens) é pelo contrário, anti-vida, no sentido de ser inter-subjetivo, comum esvaziado de emoções e sofrimentos. Se eu pudesse fazer coincidir estes dois reinos teria articulado a riqueza da vivência na relativa imortalidade do símbolo. Reformulando, é esta minha obra a tentativa de imortalizar o fugaz e dar sentido ao efêmero. Para poder fazê-lo, é óbvio que devo fixar o próprio instante no qual a vivência se derrama para o símbolo, no caso para a letra. 
Não é possível tentar localizar este escrito através da obra da artista. É verdade que, em diversos momentos Mira utilizou letras e palavras em sua obra como, por exemplo, na série Objetos Gráficos, de 1960. No entanto, sua tentativa de captar a passagem das coisas as palavras está presente em toda a obra, mesmo quando ela não se serve de letras ou palavras para expressá-la. De qualquer modo, essa tentativa de localização é o que menos importa, diante da densidade da fala de Mira sobre seu próprio trabalho. Interessa-nos ressaltar o que a artista nomeia como seu maior intuito e a forma pela qual este é descrito.

sPara que possamos melhor entender o que Benjamin nomeia como "redução ao gesto" precisamos nos deter na segunda parte do texto sobre Kafka, "uma fotografia de criança", onde o filósofo atém-se a uma foto de infância do escritor. Nesta, Benjamin vê uma imensa tristeza nos olhos do menino. E escreve: "Essa tristeza profunda foi talvez um dia compensada pelo fervoroso desejo de ser índio" (BENJAMIN, 1996[1934], p. 144). Esse desejo, nos relata Benjamin, Kafka o expressa em sua obra através de um personagem que se encanta pelo chamado do "teatro livre de Oklahoma". No texto kafkiano, o personagem Karl Rossmann adentra, através do teatro de Oklahoma, o universo da China. Já Benjamin adentra, através desse texto, a importância do gesto na obra de Kafka. De que maneira? Ele aponta, inicialmente, a relação que Kafka estabelece entre o teatro de Oklahoma, o teatro chinês e a ideia de uma pureza elementar:

$\mathrm{Na}$ China, o homem interior é inteiramente desprovido de caráter; o conceito do sábio, encarnado classicamente por Confúcio, supõe um caráter totalmente depurado de todas as particularidades; ele é o homem verdadeiramente sem caráter, isto é, o homem médio." (BENJAMIN, 1996[1934], p. 146).

Conclui então que o que define o homem chinês "é algo de completamente distinto do caráter: uma pureza elementar dos sentimentos" (BENJAMIN, 1996[1934], p. 146) Essas relações lhe permitirão apreender uma dimensão essencial em toda a obra de Kafka:

Como quer que possamos traduzir conceitualmente essa pureza de sentimentos - talvez ela seja um instrumento capaz de medir de forma especialmente sensível o comportamento gestual - o fato é que o teatro de Oklahoma remete ao teatro chinês, que é um teatro gestual. Uma das funções mais significativas desse teatro ao ar livre é a dissolução do acontecimento no gesto. Podemos ir mais longe e dizer que muitos estudos e contos menores de Kafka só aparecem em sua verdadeira luz quando transformados, por assim dizer, em peças representadas no teatro ao ar livre de Oklahoma. Somente então se perceberá claramente que toda a obra de Kafka representa um código de gestos, cuja significação simbólica não é de modo algum evidente, desde o início, para o próprio autor; eles só recebem essa significação depois de inúmeras tentativas e experiências, em contextos múltiplos. O teatro é o lugar dessas experiências (BENJAMIN, 1996[1934], p.146). 
Ao nos ensinar que o teatro é o espaço original do gesto, Benjamin indica que a palavra - ou a imagem, ou o acontecimento - poderão ser encaminhados a uma outra expressividade, a uma outra temporalidade, a outras dimensões de linguagem quando transmutados em gesto, ou seja, quando reduzidos a uma categoria mais pura e elementar, para aquém do que é passível de representação simbólica. Benjamin cita o teatro chinês, mas podemos lembrar também o Teatro Buthô, um estilo de teatro-dança, nascido no Japão, composto por movimentos longos e leves, no qual a temporalidade é muito lenta e os gestos são de especial sensibilidade; neste estilo teatral fala-se por gestos e não por palavras. Nesse teatro que trabalha com o gesto o que se põe em jogo é a apresentação e não propriamente a representação, posto que esta última categoria se refere a uma ordem simbólica, ou seja, à produção de sentidos que são instaurados pela linguagem. Já a apresentação não está submetida ao discurso. A apresentação não cria sentidos pela via da linguagem, pela via do discurso formal, e sim pela via do sensível. Daí Benjamin frisar, em relação à obra de Kafka, que esta é "um código de gestos, cuja significação simbólica não é de modo algum evidente [...] Quanto mais se afirma a técnica magistral do autor, mais ele desdenha adaptar esses gestos às situações e explicá-los" (BENJAMIN, 1996[1934], p. 147).

\section{O TEMPO E O GESTO}

Para dar prosseguimento a esta linha de pensamento trazemos outro pequeno escrito de Mira Schendel, tratando agora de sua relação com o tempo. É interessante notar como, através de suas palavras, podemos aprender um pouco mais sobre o gesto em Benjamin:

No começo pensava que para tanto bastava eu surpreender, em mim, esta urgência da vivência para a articulação, isto é: sentar-me a esperar que a letra se forme. Que assuma a sua forma no papel, e que se ligue a outras numa escrita pré-literal e pré-discursiva. Mas sentia, desde o início, que isto poderia ter êxito apenas se o papel fosse transparente. Agora sei melhor avaliar, porque tinha então aquela impressão: a letra, ao formular-se, deve mostrar o máximo de suas faces para ela mesma.

Surgiu, no entanto, um segundo problema. A seqüência das letras no papel imita o tempo, sem poder realmente representá-lo. São simulações do tempo vivido, e não captam a vivência do irrecuperável que caracteriza esse tempo. Os textos que desenhei no papel podem ser lidos e relidos, coisa que o tempo não pode. Fixam, sem imortalizar, a fluidez do tempo (SCHENDEL apud SALZSTEIN, 1997, p. 256).

Neste trecho vemos como Mira encaminha seu pensamento muito mais para a questão da apresentação, conforme descrevemos anteriormente, do que para a representação. Especialmente quando diz "a seqüência das letras no papel imita o tempo, sem poder realmente representá-lo" a artista parece querer se 
referir a algo que precisa ser mostrado, apresentado de maneira direta, e não re-presentado, isto é, apresentado novamente pela mediação de uma imagem ou de um símbolo. A apresentação se refere a algo que pode ser apreendido sem mediações, intuído, sentido, enquanto que a representação exige um raciocínio e uma articulação simbólica. Mira usa o exemplo do tempo para tratar dessa questão: a sequência das letras indica a passagem do tempo e podemos apreendêla de maneira imediata, mas não somos capazes de representá-la, porque o tempo é, de fato, irrepresentável. Santo Agostinho, no século III, já teria colocado muito bem essa questão, ao procurar, em vão, estabelecer uma definição conceitual do tempo. "O que é, por conseguinte, o tempo? Se ninguém me perguntar, eu sei, Mas se quiser responder a quem me fez a pergunta, já não sei." (AGOSTINHO, 1984, p. 304). Isso não significa que minha intuição ou apreensão direta a esse respeito não tenha sentido. Mas esse sentido não depende de palavras ou de conceitos para ser produzido. É nesse mesmo registro que podemos olhar os trabalhos de Mira Schendel. Há, sem dúvida, sentidos sendo criados na tela e, principalmente, sentidos que são criados quando as olhamos; no entanto, estes sentidos provêm da nossa relação com o sensível e não com a linguagem verbal. O que equivale a compreender o sensível como um conjunto de forças sem significação verbal; são intensas e imprevisíveis forças sensoriais.

Schendel também ressalta, em sua fala, a impossibilidade de representação do tempo, e evidencia a impossibilidade de se captar a "vivência do irrecuperável". Com esta belíssima expressão, Mira nos remete à incompletude de nossa condição, mas também à incompletude da letra e da palavra. Com isso aponta que sempre há um algo "irrecuperável”, inatingível, à nossa volta.

A questão temporal está colocada na fala da artista também de uma outra maneira. Não apenas porque a sequência das letras no papel imita o tempo, como ela diz, mas também porque sua necessidade sempre renovada de apreender o inapreensível é por ela descrita como uma tentativa de "surpreender a urgência da vivência para a articulação". Trata-se de um modo diferente de situar, em sua obra, a importância do imediato. Na fala da artista, entretanto, a expressão "urgência" não aponta apenas para a dimensão temporal; ela também evoca o assombro de lidar, simultaneamente, com a finitude da vida e com o vigor dos sentimentos que ela nos faz experenciar. Entre o gesto e o assombro da existência: eis como podemos situar o seu trabalho. É também a dimensão que Benjamin deseja frisar na obra kafkaniana: "Kafka não se cansa de dar corpo ao gesto, em descrições desse tipo. Mas sempre com assombro." (BENJAMIN, 1996[1934], p. 162). Trata-se, por fim, não só do espanto inerente à existência, mas sobretudo do impacto que uma obra de arte poderá causar ao descentrar o espectador de seu trivial conforto perceptivo. O assombro se refere ao plano mais amplo da vida, mas também ao plano mais específico da estética, do fato plástico, quando não se trata de beleza ou feiúra, e sim da obra de arte enquanto causadora, suscitadora de sensações e sentimentos.

Há ainda um outro aspecto a ser ressaltado na fala de Mira Schendel: a escrita "pré-literal ou pré-discursiva". É importante ressaltar, em primeiro lugar, que tratar do inominável e do vazio não nos conduz à impossibilidade de usar 
palavras ou imagens. Na verdade, são justamente elas - e o limite delas - que podem ser utilizadas para indicá-lo. Mas isso suscita uma forma de experiência com a linguagem, experiência na qual se expressa ou se vislumbra, por meio de palavras ou de imagens, alguma coisa que elas, de fato, não poderiam dizer. É o que busca Clarice Lispector quando escreve: "Cada coisa tem um instante em que ela é. Quero apossar-me do é da coisa" (LISPECTOR, 1998, p. 9). Teríamos outro exemplo em Paul Celan, conhecido pela linguagem dura e direta com a qual fazia seus poemas. Dizia que desse modo construía "cercamentos em torno do sem palavra, sem limites" (CELAN, 1983, p.20). Kafka faria o mesmo na literatura, ao usar uma escrita dissecada e recusar-se a inflá-la com rebuscamentos, metáforas e outras figuras de linguagem. Kafka não teria se servido de metáforas nem mesmo quando escreveu A metamorfose, como ele mesmo nos indica: "As metáforas são uma das coisas que me fazem perder a esperança na literatura" (DELEUZE; GUATTARI, 1977, p. 123). É como se através da palavra, da escrita, da letra, Kafka quisesse atingir um região na qual elas não chegam, ou chegam apenas enquanto envoltório do indizível. Através da escrita, o que ele tenta apreender é o gesto inaugural de toda escrita.

Neste ponto a dimensão do tempo aparece, sob uma outra face, no trabalho de Mira Schendel: seu esforço é o de apreender o tempo e o gesto das origens, um momento anterior ao envoltório do indizível, ou o momento fugaz no qual o envoltório está sendo criado para circunscrever o vazio. Por este motivo, Mira recusa o uso de adornos estéticos que, ao sofisticar o envoltório, disfarçam o vazio que existe em seu núcleo. Sua obra pretende apreender o gesto inaugural de toda linguagem, seja ela verbal ou plástica. Ela quer, em suas próprias palavras, "surpreender o discurso no momento de sua origem", "captar a passagem da vivência imediata para o simbólico". Para chegar a esse gesto é preciso reduzir a narrativa, minimizar os recursos pictóricos, esvaziar os ornamentos. Essa é a estratégia de Mira, e ela nos convoca a fazer o mesmo. Sua via de acesso ao gesto não poderia ser a estrutura linguística do pensamento, pois o gesto é anterior a todo discurso e a toda forma. Do mesmo modo, para experimentar e fruir seu trabalho, devemos abandonar as formas discursivas e o pensamento formalmente estruturado para nos comunicarmos com aquilo que em nós pertence ao campo de sensações.

Afirmar que a obra de Mira possui uma proximidade com uma dimensão "pré-literal ou pré-discursiva", conforme a artista mesma a define, significa dizer que está relacionada à sensação e aos sentidos. Quando adentramos o terreno do inapreensível, ou seja, o terreno do gesto, os primeiros contatos com este campo acontecem pela via dos sentidos, e não pela via do pensamento formal. Embora a linguagem e a letra se encontrem presentes, o que está em jogo é o "sentido" em sua dupla expressão - aquilo que se sente e o sentido da experiência.

Encontramos no crítico e curador Paulo Venâncio Filho (2013, p. 311312) um comentário sobre a obra de Mira que muito bem sintetiza o que aqui foi colocado:

A temporalidade é decisiva no trabalho de Mira. O tempo, o fluxo, a memória, a duração. Temos a impressão de estar 
diante do desenvolvimento de apuradas técnicas visuais imersas no fluxo temporal. Por isso o interesse pelo tênue, pelo ínfimo, pelo sutil corresponde à aceitação daquilo que não pode ser medido, calculado, quantificado. Fenômenos que escapam aos modos de registros tradicionais, que acontecem numa região sem dimensões, sem coordenadas, espacialmente indeterminada. Temporalmente também. Não se pode dimensionar o vazio. E é esse vazio que é ativado por uma presença desinteressada apenas. Uma presença muitas vezes mal definida, quase informe, quase imperceptível - suspensa. As coisas estão em estado de suspensão. Elas devem estar em contraste com o inerte, o vazio, o branco, o transparente. $\mathrm{O}$ vazio precisa ser intensificado para que a efemeridade quase ínfima do fenômeno possa se manifestar visivelmente. O vazio então é ativo, é contraste. Daí as condições que presidem a execução do trabalho.

O tempo é presente na obra de Mira no mesmo sentido em que o gesto, conforme elaborado por Benjamin, encontra-se aí presente. $\mathrm{O}$ gesto habita justamente essa região "sem dimensões, sem coordenadas, espacialmente indeterminada". Daí sua relação íntima com o tempo. O tempo é indeterminado, pois não se trata de precisá-lo; ao contrário, trata-se de estendê-lo e de experimentálo em sua possibilidade criativa, ou seja, sua possibilidade de transformar e de criar novos movimentos, novas intensidades. Neste ritmo temporal, a singularidade comparece e se reinventa ao "escapar aos modos de registro tradicionais", atendose ao que é imperceptível, fluido, ínfimo.

A fala de Venâncio Filho entra em correspondência com a fala de Mira exposta como epígrafe deste artigo. O vazio, o âmago da obra de Mira, é ativado por meio de técnicas e criações em que estão presentes movimentos lentos, silenciosos, intensos, sutis. Como diz Venâncio Filho, comparece uma "presença desinteressada". Presença que se expõe sem definição, sem alarde, sem contornos nítidos ou formas enfáticas. Quase não há nada. Quase não se percebe a presença de uma poética; porém, exatamente por afirmar este modo de presença é que a artista alcança a sua singular e quase volátil aparição. Será exatamente este quase nada que presentificará o gesto. Quase não há nada para que haja apenas o gesto, a redução da imagem ao gesto, a dissolução da imagem no gesto. Venâncio ressalta que "o vazio precisa ser intensificado para que a efemeridade quase ínfima do fenômeno possa se manifestar visivelmente", ou seja, o efêmero comparece como gesto. $\mathrm{O}$ invisível e o efêmero aparecem no visível da imagem artística em forma de contundência sutil, de um vazio eloqüente. Ao inaugurar este paradoxo, as entrelinhas do visível tornam-se presentes, passam a ser percebidas, vistas. Intensificar o vazio, nesse sentido, é reduzir ao gesto. 


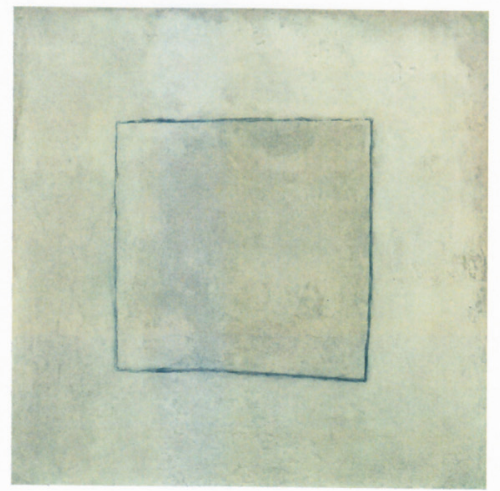

Fig. 2

Sem Título, 1965

óleo sobre papel, $43 \times 47 \mathrm{~cm}$

coleção particular

\section{O VAZIO E A PROFUSÃo de SENTIDOS}

O gesto seria inominável por ser anterior aos nomes; ele não poderia ser designado por nome algum, nem pertencer a nenhum lugar no discurso trivial, conhecido, narrativo e lógico. O inominável presente na obra de Mira Schendel é o que não se encontra visível. O observador, tocado em sua sensibilidade e a partir do vazio, do silêncio e da solidão que a contemplação exige, poderá criar algum sentido para o que, originalmente, não possui sentido algum. Nesta via reflete o escritor Santiago Klovadloff (2003, p. 132):

O que não podemos captar é aquilo a que primordialmente se aspira a transluzir como verdade, quando se pinta renunciando a toda aspiração reprodutiva. E que se deseje intensamente transluzir o que não se pode capturar não significa, obviamente, que seja possível retratá-lo, posto que já não se tenta plasmar alguma coisa, mas sim algo que não é.

Pintar para que o invisível permita que as suas impressões sejam sentidas no visível. É disso que se trata. Invisibilidade e silêncio são, aqui, sinônimos perfeitos. O invisível e o indizível são correspondentes em uma exigência unívoca feita ao verdadeiro pintor pelo seu próprio espírito. Porque, 
enquanto se colocam em movimento, ou melhor, enquanto se percebe que assim estão, as coisas já não se deixam manipular como dóceis objetos de nosso entorno. Em vez disso, convertem-se em poderosas insinuações que nos expressam em nossa condição de desejosos, de seres ávidos por uma totalização jamais cumprida.

O autor condensa toda a sua fala ao dizer: "Pintar para que o invisível permita que as suas impressões sejam sentidas no visível. É disso que se trata. Invisibilidade e silêncio são, aqui, sinônimos perfeitos" (KLOVADLOFF, 2003, p. 132). Neste sentido, os elementos do vazio, do silêncio e da solidão se articulam e encontram o seu ápice, pois este "invisível” se refere ao sensível enquanto conjunto de forças intensas que irrompem sem uma direção determinada. Aparece assim outro paradoxo relacionado ao gesto. Ele é vazio enquanto forma, direção precisa, possibilidade de nomeação. Mas é, paradoxalmente, cheio de potencialidades ao inaugurar todas as formas e todos os nomes. Daí podermos entender essa inusitada combinação, no trabalho de Mira, entre a economia e a intensidade, o vazio e a profusão de sentidos. É coerente que só possamos apreendê-lo a partir do campo sensível, já que este campo é, a um só tempo, vazio de significações verbais e pleno de intensas e imprevisíveis forças sensoriais. É a essa profusão de sensações que se refere José Gil (2005, p. 23) ao tratar da fonte criadora do artista:

$\mathrm{O}$ artista volta incessantemente a esta massa primitiva. É o seu reservatório de experiência, de onde tira a força virgem das suas formas: ao mesmo tempo, refaz um mundo já mais ou menos moldado pela linguagem. A sua experiência não é pura, mistura imagens atuais e imagens arcaicas, emoções que acabam de irromper e recordações de emoções; esta mescla torna-se então a condição da imagem nova, essa imagem vinda sempre não se sabe de onde - porque vinda do caos original que é necessário ao artista reativar sem descanso.

Assim, ao dizer que o pintor não se atém a "plasmar alguma coisa, mas sim algo que não é", Klovadloff (2003, p. 132) se refere a algo que não é enquanto coisa, porém deixa marcas, produz impressões, cria sentidos. Uma espécie de força primitiva e informe que não é representação e sim, apresentação, conforme explanação anterior. Ao pintar, o artista quer mostrar esse invisível, e desse modo a força adquire a forma de determinada imagem, determinada obra de arte. Quando falamos em forma de uma força, não significa que esta seja uma forma com clara definição simbólica; ao contrário, no que se refere à obra de Mira Schendel, dar forma a um conjunto de forças resulta em trabalhos altamente expressivos e voltados muito mais ao sensível do que ao simbólico.

Este ponto, entretanto, exige uma ressalva, pois o "invisível” encontra-se, paradoxalmente, ligado à linguagem. A impossibilidade de dizer, perante um trabalho de Mira Schendel, encontra-se referida ao fato de que este não apresenta um sentido simbólico nem se articula, ao menos a princípio, simbolicamente. Todavia, é a partir de nossa inserção em uma ordem simbólica que percebemos 
a lacuna e o vazio presentes na obra da artista. Apenas com base nessa ordem seu trabalho ativa o vazio. Na perspectiva do gesto, trata-se de um obra que ativa um espaço e um tempo potenciais, informes e indeterminados, mas a partir dos quais se dão todas as formas e determinações. Aí reside a singularidade e a força sensorial do trabalho de Mira, capaz de ativar, através de uma estratégia redutora, uma profusão de sentidos.

\section{REFERÊNCIAS}

AGOSTINHO. Confissões. Porto: Apostolado da Imprensa, 1984.

BENJAMIN, W. Franz Kafka: a propósito do décimo aniversário de sua morte (1934). In . Magia e Técnica, Arte e Política. São Paulo: Brasiliense, 1996. Coleção Obras Escolhidas, v. 1, p. 137- 164.

BRETT, G. Ativamente o vazio. In: BASBAUM, R. (Org.). Arte Contemporânea Brasileira. Rio de Janeiro: Marca D’Água, 2001. p. 66- 72.

CELAN, P. Gesammelte Werk in fünf Bänden. Frankfurt: Suhrkamp, 1983.

DELEUZE, G; GUATTARI, F. Kafka: por uma literatura menor. Rio de Janeiro: Imago, 1977.

GIL, J. A imagem-nua e as pequenas percepções: estética e metafenomenologia. Lisboa: Relógio D’Água, 2005.

KLOVADLOFF, S. O silêncio primordial. Rio de Janeiro: J. Olympio, 2003.

LISPECTOR, C. Água viva. Rio de Janeiro: Rocco, 1998.

SAlZSTEIN, S. (Org.). No vazio do mundo: Mira Schendel. Rio de Janeiro: Marca D’Água, 1997.

SYLVESTER, D. Entrevistas com Francis Bacon: a brutalidade do fato. São Paulo: Cosac \& Naify, 1998.

VENÂNCIO FILHO, P. A presença da arte. São Paulo: Cosac \& Naify, 2013.

Recebido em: 02 de julho de 2014 Aceito em: 03 de setembro de 2014 